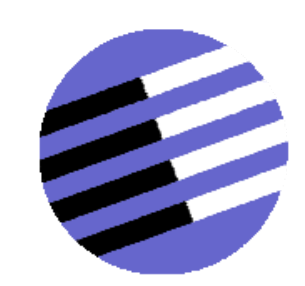

GOVERNANCE AND THE EFFICIENCY

OF ECONOMIC SYSTEMS

GESY

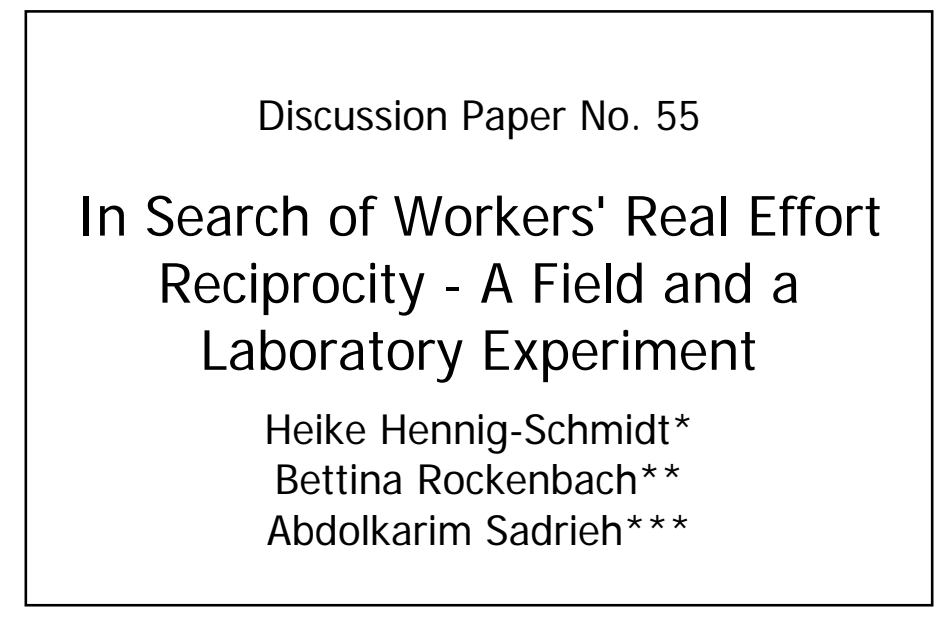

July 2005

*Heike Hennig-Schmidt, Laboratory of Experimental Economics, University of Bonn, Adenauerallee 24-42, 53113 Bonn, Germany, Tel. +49 228 7391-95 (Fax -93), http://www.bonneconlab.uni-bonn.de, hschmidt@uni-bonn.de

**Bettina Rockenbach, Lehrstuhl für Mikrooekonomie, Universitaet Erfurt, Postfach 900 221, 99105 Erfurt, Germany, Tel. +49 361 73745-21 (Fax: -29), http://www.uni-erfurt.de/mikrooekonomie, bettina.rockenbach@uni-erfurt.de ***Abdolkarim Sadrieh, Faculty of Economics and Management, University of Magdeburg, Postbox 412039016 Magdeburg, Germany, Tel. +49 391 67-18492 (Fax. 11355), http://www.ww.unimagdeburg.de/ebusiness/, sadrieh@ww.uni-magdeburg.de

Financial support from the Deutsche Forschungsgemeinschaft through SFB/TR 15 is gratefully acknowledged. 


\title{
In Search of Workers' Real Effort Reciprocity - A Field and a Laboratory Experiment
}

\author{
Heike Hennig-Schmidt, University of Bonn \\ Bettina Rockenbach, University of Erfurt \\ Abdolkarim Sadrieh, University of Magdeburg
}

July 2005

\begin{abstract}
We present a field experiment to assess the effect of own and peer wage variations on actual work effort of employees with hourly wages. Work effort neither reacts to an increase of the own wage, nor to a positive or negative peer comparison. This result seems at odds with numerous laboratory experiments that show a clear own wage sensitivity on effort. In an additional real-effort laboratory experiment we show that explicit cost and surplus information that enables to exactly calculate employer's surplus from the work contract is a crucial pre-requisite for a positive wage-effort relation. This demonstrates that employee's reciprocity requires a clear assessment of the surplus at stake.
\end{abstract}

\section{$\underline{\text { Keywords }}$}

efficiency wage, reciprocity, fairness, field experiment, real effort

$\underline{\text { JEL Codes }}$

C91, C92, J41

\section{Acknowledgements}

We thank Heidi Schrader and Anke Schmalenbach for research assistance. We are grateful for helpful suggestions on our work by participants of the experimental economics research seminar at Bonn University, the ENDEAR Workshop 2003, Amsterdam, the ESA 2004 International Meeting, Amsterdam, and the GEW 2004 Annual Meeting, Prague. Furthermore, we thank Reinhard Selten for his insightful comments. Our research was financially supported by Deutsche Forschungsgemeinschaft (SFB 303 and SFB/TR 15) and EU-TMR Research Network ENDEAR (FMRX-CT98-0238).

Contacting the Authors*

\footnotetext{
Heike Hennig-Schmidt

Laboratory of Experimental Economics

University of Bonn

Adenauerallee 24-42

53113 Bonn, Germany

Tel. +49 228 7391-95 (Fax -93)

http://www.bonneconlab.uni-bonn.de hschmidt@uni-bonn.de
}

Bettina Rockenbach Lehrstuhl für Mikrooekonomie Universitaet Erfurt Postfach 900221 99105 Erfurt, Germany Tel. +49 361 73745-21 (Fax: -29) http://www.uni-erfurt.de/mikrooekonomie bettina.rockenbach@uni-erfurt.de
Abdolkarim Sadrieh Faculty of Economics and Management University of Magdeburg Postbox 4120 39016 Magdeburg, Germany Tel. +49 391 67-18492 (Fax. 11355) http://www.ww.unimagdeburg.de/ebusiness/ sadrieh@ww.uni-magdeburg.de

*) Please, direct correspondence to the first author, preferably by email. 


\section{Introduction}

In efficiency wage models, a wage increase in excess of the market clearing wage can induce an increase in the productivity of labor and, thus, be beneficial to a profit-maximizing firm. The perhaps most popular explanation for the positive correlation of wage and productivity is the fair wage-effort model, in which workers increase (reduce) the effort exerted, if the wage paid is greater (smaller) than the wage they perceive as the fair wage (Akerlof 1982; Summers 1988; Akerlof and Yellen 1990). The original reasoning for such reciprocal behavior of workers is based on the notion of cognitive dissonance reduction (Adams and Rosenbaum 1962; Akerlof 1982) which basically introduces a disutility from being over-paid or underpaid (i.e. receiving a wage above or below the perceived fair wage, respectively). To avoid the disutility of cognitive dissonance, workers can either adjust their beliefs concerning the fair wage (Adams 1963) or adjust their effort level in order to align the fair and the received wage (Akerlof 1982). To complicate matters even further, a number of different parameters have been suggested in the literature that may influence the wage level that is perceived as fair. These include the own past wage, the wage of other individuals in a "reference set" (e.g. a peer group or a group of superiors), and the general work environment. However, the extent, the direction, and the interplay of these factors all remain open issues for empirical research.

In numerous experiments, work situations have been modeled where subjects are assigned to the roles of the employer and the employees, respectively, and effort exertion is simulated by effort level choices. These studies (see Fehr, Kirchsteiger Riedl 1993, Fehr, Kirchler, Weichbold, Gächter 1998, Fehr and Falk 1999, Charness 2004) provide the robust observation that an increased wage is reciprocated by an increased effort. Fahr and Irlenbusch (2000) and Gneezy (2004) identify a positive wage effort relation also in laboratory experiments with real effort exertion. In this paper, we report a field and a laboratory experiment that extend these studies in two dimensions. First, we increase the authenticity of the work situation by experimenting with employees who receive real work contracts, produce valuable output and perform natural work tasks. ${ }^{1}$ Second, we systematically vary the peer wage and the employer's surplus information to identify which information is crucial for observing a positive wage-effort relation.

\footnotetext{
${ }^{1}$ There are a number of other studies using field experiments in a labor context. Erev, Bornstein and Galili (1993) compare piece-rate payments in an inter-group competition. Dickinson (1999) and Fehr and Götte (2002) study labor supply under variation of piece rate wages. Harrison and List (2004) propose a taxonomy of field experiments and provide an overview over the recent studies.
} 
The results of our field experiment are surprisingly clear. We find no treatment effects whatsoever. Neither wage increases nor information on peer wages have a significant influence on the workers' effort. This result seems at odds with the numerous laboratory experiments that show a positive wage-effort relationship. We conjecture that the information on employer's cost and surplus, which is available in the laboratory experiments, but absent in the field, may be the cause for our negative findings. To solve the puzzle, we conduct a laboratory experiment, in which we study a similar work situation as in the field experiment with real - not simulated - effort exertion and a variation of the wages. The extension of our design compared to the existing literature is the controlled variation of information on the employer's surplus from the work relation. This allows us to assess the impact of employer surplus information on employee's reciprocal behavior. Previous work (Mitzkewitz and Nagel 1993, Irlenbusch and Sliwka 2003) indicates that this type of incomplete information may have a negative impact on cooperation, because the reference point for fair behavior is not available to the employees.

Our laboratory experiment gives support to our conjecture that a positive wage-effort relationship is only observed in the presence of employer surplus information. Comparing all treatments from both our experiments, we find that only in the case of full information, wage increases can be profitable as predicted by the fair wage-effort hypothesis. We conclude that mutual surplus information is crucial for reciprocal employment relationships in real effort settings.

\section{The Field Experiment with Real Effort}

In the field experiment, student workers were hired by a research institution of the University of Bonn (Sonderforschungsbereich 303). The subjects performed a real work task that required a substantial amount of effort. They typed the abstracts of research papers that were not yet available electronically into an internet database in order to enhance the accessibility of research output. ${ }^{2}$ The work environment was a typical university office. Student workers were contacted by a project manager who was neither a student nor part of the local staff ${ }^{3}$. In

\footnotetext{
2 Abstracts of the papers that were still available at the time of the experiment can be found at http://www.wiwi.uni-bonn.de/sfb303/sonderforschungsbereich.eng.html

${ }^{3}$ We employed a primary school teacher, who had just graduated and who had no obvious connection to the laboratory of experimental economics. None of the experimenters had contact to the typists.
} 
total, 103 students of the University of Bonn, most of them with majors in law or economics, were recruited for our field experiment. ${ }^{4}$

Each subject had to work for two hours on two separate occasions of one hour each. On the first occasion, the typists were asked to arrive 20 minutes before the work hour in order to receive instructions and a brief training. The instructions (ca. $10-15$ minutes) not only explained the technical details of the job, but also explained the value of the work for the university $^{5}$. It was made absolutely clear that the job was to be taken very seriously. No reference was made to the fact that wages in some treatments would be varied in the second occasion. The instructions also explained that the project was being used for a pilot study on the division of work load.

Following the instructions, each typist went through a brief training (ca. 5 - 10 minutes) that consisted of typing an abstract similar to those actually used in the data set. ${ }^{6}$ Immediately following the training, each typist received a folder containing the abstracts, keywords, and JEL-classification numbers that had to be entered, and the first hour of work commenced. After one hour sharp, the project coordinator terminated the first session, making sure that all data was saved. On the second occasion, no further instructions were given and the second hour of work proceeded in the same way as on the first occasion.

Each typist performed the job alone in a typical university office on a typical office computer. In addition to the normal items found in such an office, some up-to-date newspapers and magazines were placed in the room. Furthermore, the computer was configured in such a way that the icons for some of the standard computer games provided by the operating system were placed close to the icons for the abstract typing software. During the working hours the typists were left unobserved. The typists knew that the project coordinator was next door, but since they were told to call the project coordinator in case of problems, the setup provided no indication of unexpected controls during the work hour.

Typists were promised a flat fee of DM 10 ( $\approx$ Euro 5) for showing up on time, plus an hourly wage of DM 20 for each hour of typing. This hourly wage was slightly above average in the typical wage distribution for students' jobs, which at the time was in the range from DM 15 to DM 22. The typists were told they would receive their payment only after having completed

\footnotetext{
${ }^{4}$ There were 42 female and 61 male typists.

${ }^{5}$ The instructions are contained in Appendix B1. It was explained to the typists that they would be able to see the results of their work (i.e. the typed abstracts) on the institute's research website.

${ }^{6}$ All typist were trained using the same abstract.
} 
both working hours. In total, subjects were paid a flat fee of DM 50 to DM 58 depending on the treatment.

\section{$2.1 \quad$ Treatments of the field experiment}

For the first hour of work, the typists in all treatments received a previously announced wage, which was in the range of wages for comparable student jobs. Before the second hour of work, the typists - in some treatments - were informed about an unexpected pay raise and in some treatments - about the pay raise of a peer group. To avoid contamination, the second work hours were scheduled after all subjects had completed their first work hour. In those treatments, in which the wage was varied, the project coordinator informed each typist of the new wage before the typist started to work. The wording used by the project coordinator to inform the typists was fixed by the experimenters beforehand and always presented exactly in the same manner.

Treatment F0 was our control treatment in which the typists received no pay raise and no information on peer groups. In treatment F10, typists received a 10 percent pay raise, but received no information on peer groups. In treatment F40peer, typists received a 40 percent pay raise and were informed that the typists in the previous group F10 had received a lower pay raise of 10 percent. Finally, the group F10peer received a 10 percent pay raise and was informed that the previous group F40peer had received a substantially higher pay raise of 40 percent. Over all treatments, we had 103 independent observations. Table 1 summarizes the four treatments of our field experiment.

Table 1. Treatments in the field experiment

\begin{tabular}{|c|c|c|c|c|}
\hline Treatment & F0 & F10 & F40peer & F10peer \\
\hline Show-up fee (in DM) & 10 & 10 & 10 & 10 \\
\hline Wage $1^{\text {st }}$ hour (in DM) & 20 & 20 & 20 & 20 \\
\hline Wage $2^{\text {nd }}$ hour (in DM) & $20(+0 \%)$ & $22(+10 \%)$ & $28(+40 \%)$ & $22(+10 \%)$ \\
\hline $\begin{array}{l}\text { Information on peer } \\
\text { reference group }\end{array}$ & no & no & $\begin{array}{c}\text { yes } \\
\text { smaller increase of } \\
\text { preceding group: }+10 \%\end{array}$ & $\begin{array}{c}\text { yes } \\
\text { greater increase of } \\
\text { preceding group: }+40 \%\end{array}$ \\
\hline Number of typists & 24 & 25 & 23 & 31 \\
\hline
\end{tabular}

\section{$2.2 \quad$ Hypotheses}

According to a positive wage-effort relationship we expect subjects in F10 to exhibit higher efforts than subjects in F0. The higher wage as well as the favorable peer comparison should lead to even higher efforts in F40peer compared to F10. If peer comparison plays a role, the 
unfavorable peer information in F10peer should lead to lower efforts than in F40peer and in F10, where the same pay increase is made, but without the peer comparison.

\subsection{Results of the Field Experiment}

We base our data analysis on two measures we observe for every typist: the usable output (i.e. the number of correctly typed words) and the erroneous output (i.e. the number of incorrectly typed words). ${ }^{7}$ Usable output is an immediate measure of output quantity, but it is insufficient as an indicator of productivity, because it does not capture the cost of correcting erroneous production. ${ }^{8}$ Thus, the evaluation of a typist's productive effort should also take into account the output quality (i.e. the ratio of usable output to total production).

Table 2: Treatment averages in the field experiment

\begin{tabular}{|c|c|c|c|c|c|}
\hline & & F0 & F10 & F40peer & F10peer \\
\hline \multirow{3}{*}{$\begin{array}{l}\text { Output quantity } \\
\text { (in words per minute) }\end{array}$} & $1^{\text {st }}$ hour & 16.887 & 17.301 & 15.592 & 16.929 \\
\hline & $2^{\text {nd }}$ hour & 17.521 & 17.453 & 16.051 & 17.211 \\
\hline & $2^{\text {nd }}$ minus $1^{\text {st }}$ hour $*$ & .634 & .152 & .459 & .282 \\
\hline \multirow{3}{*}{$\begin{array}{l}\text { Errors } \\
\text { (in words per minute) }\end{array}$} & $1^{\text {st }}$ hour & .373 & .290 & .268 & .367 \\
\hline & $2^{\text {nd }}$ hour & .412 & .300 & .303 & .379 \\
\hline & $2^{\text {nd }}$ minus $1^{\text {st }}$ hour $*$ & .040 & .010 & .035 & .011 \\
\hline \multirow{3}{*}{ Output quality } & $1^{\text {st }}$ hour & .978 & .983 & .984 & .979 \\
\hline & $2^{\text {nd }}$ hour & .978 & .982 & .982 & .978 \\
\hline & $2^{\text {nd }}$ minus $1^{\text {st }}$ hour $*$ & -.001 & -.002 & -.002 & -.001 \\
\hline
\end{tabular}

*) The reported average of all differences may slightly deviate from the difference of the averages, due to rounding errors.

Table 2 shows the averages of output quantity, error, and output quality observed in each working hour of each of the four treatments. Additionally, the average change of each measure from the first to the second working hour is reported. In our analysis, we control for subjects' fixed effects. Note that the within-subject design ensures that individual differences (e.g. in typing capabilities) are cancelled out by using each subject's first-hour performance as a control for the second-hour performance. Since all subjects were treated equally in the first hour, any cross-treatment difference in the change of subjects' performance must be due to

\footnotetext{
${ }^{7}$ Misspelled words and deviations from the original text (omissions or additions) were counted as errors. Multiple errors in the same word were counted as a single error. Two independent secretaries checked all the abstracts, counting the correct words as well as the errors. The counts were double-checked when necessary.

${ }^{8}$ There were real costs of correction, because the abstracts were corrected by secretaries before being published on the internet.
} 
the corresponding treatment variation. If we, however, find no significant treatment differences concerning the change in performance, then we must conclude that the treatment variation has had no discernible effect on subjects' behavior.

We base our analysis on the following measures, (1) output difference: second hour minus first hour quantity; (2) quality difference: second hour minus first hour quality. For each treatment, the vertical line in Figure 1 visualizes the range of output changes, and the horizontal line marks average output.

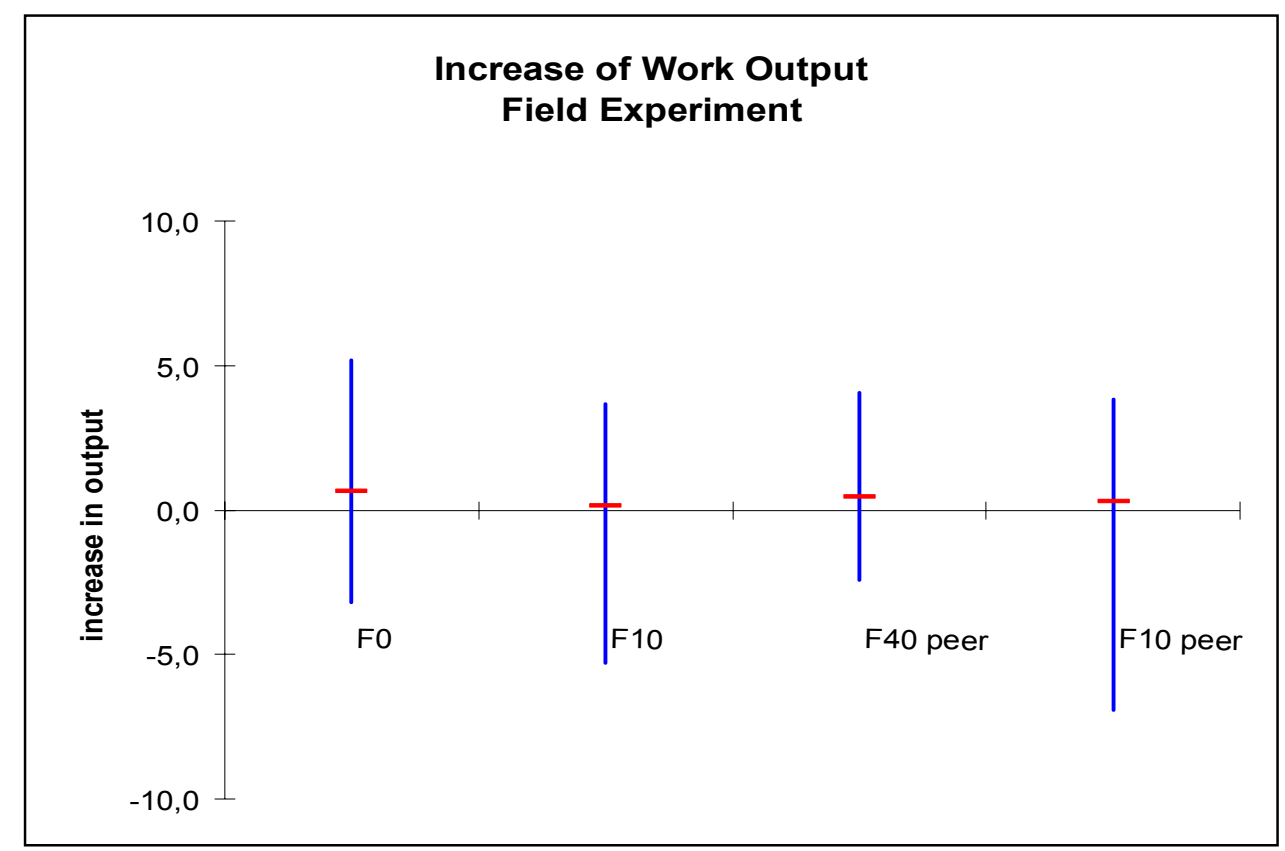

Figure 1: Increase of work output in the field experiment

We find no treatment effects whatsoever. The increase in own wage has no effect on the provided work effort measured by correct output or output quality. There is also no effect of the availability of peer wage information on work output, neither when the own wage is higher nor when it is lower than the peer group's wage. ${ }^{9}$ Hence, as far as our student typists are concerned, increasing wages is not at all a profitable action for the employer. There also seems to be no need for wage compression (i.e. reducing the distribution spread of wages in the company) or for wage secrecy, both of which are sometimes believed to increase employer profits.

\footnotetext{
${ }^{9}$ The results of the statistical comparisons are given in Table A1 in Appendix A.
} 


\section{How do our Field Experiment Results compare to the Existing Literature?}

The field experiment exhibited no significant sensitivity of exerted work effort both in own wage increases and in peer wage comparisons. The lacking sensitivity to peer wage comparisons is in accordance with laboratory experiments by Charness and Kuhn (2004). However, the lacking sensitivity of effort to own wage is in sharp contrast to observed behavior in previous laboratory experiments that detect a positive wage-effort relationship (Fehr, Kirchsteiger Riedl 1993, Fehr, Kirchler, Weichbold, Gächter 1998, Fehr and Falk 1999, Charness 2004). How can the striking difference between those results and the observations in our study be explained? There are two main features that distinguish our experiment from the ones mentioned above. First, the effort exertion is real and not simulated. However, laboratory experiments with real effort exertion by Fahr and Irlenbusch (2000) and Gneezy (2004) also find a positive wage-effort relation and hence indicate that this difference cannot be the cause of lacking sensitivity. The second major difference is that the laboratory experiments give more detailed information about the relevant model parameters than is available in the field. All these experiments provide subjects with common knowledge on employer's surplus from work effort. In addition, in the laboratory experiments with induced effort cost, subjects generally have common knowledge on employee's effort cost. In particular, this allows every player to exactly calculate the surplus that each side of the work relationship gains. In the field experiment, these parameters are at best partially known to the respective parties. The lack of surplus information complicates the assessment of fairness and, thus, may dampen reciprocity.

\section{A Laboratory Experiment with Real Effort}

We conducted a laboratory experiment to analyze whether information about relevant model parameters in labor relations may be the cause for observed differences in exerted efforts. We study a real-effort work situation in the laboratory that closely resembles our field experiment's setup. In contrast to the field experiment, however, we control the information of the workers on the employer's surplus. We distinguish between a situation in which the employee is completely informed about the employer's surplus from work effort and a situation in which no such information is available.

We implemented a work task that was simple to perform, that was physically not overly demanding, and that asked for no special knowledge. Moreover, we required the output of the 
work task to be easily measurable and to allow for considerable variance. Performing a similar task as in Falk and Ichino (2003), our subjects folded a letter and enveloped it. ${ }^{10}$

In total, 59 subjects participated in our laboratory experiment. The experiment was conducted at the Erfurt Laboratory for Experimental Economics (elab), University of Erfurt. Upon arrival, subjects were seated in separate cubicals containing a pile of letters, a pile of envelopes, and written instructions on the experiment (see appendix B.2). ${ }^{11}$ After having read the instructions, a monitor demonstrated the work process and answered questions. The work task was divided into two units of 15 minutes each. Between the two units, there was a break of 5 minutes in which the monitor collected the filled envelopes. At the beginning of the second unit, subjects received the instructions for the second unit. After the experiment, subjects were paid their wage. Total average session time was 45 minutes.

\subsection{Treatments of the laboratory experiment}

Our laboratory experiment comprises variations of the two treatments F0 and F10 of the field experiment. In the baseline treatment L0, subjects were paid the same amount for the first and the second work unit, while in treatment L10 subjects received a wage increase of ten percent in the second work unit. Both treatments were conducted under two information conditions: no information (L0 and L10) and information on the employer's surplus from work effort (L0surplus and L10surplus). Table 3 summarizes the four treatments of our laboratory experiment.

Table 3. Treatments in the laboratory experiment

\begin{tabular}{lcccc}
\hline Treatment & L0 & L10 & L0surplus & L10surplus \\
\hline Show-up fee & 1.50 Euro & 1.50 Euro & 1.50 Euro & 1.50 Euro \\
$1^{\text {st }}$ work unit wage $(15 \mathrm{~min})$ & 2.50 Euro & 2.50 Euro & 2.50 Euro & 2.50 Euro \\
$2^{\text {nd }}$ work unit wage $(15 \mathrm{~min})$. & 2.50 Euro & 2.75 Euro & 2.50 Euro & 2.75 Euro \\
& $(+0 \%)$ & $(+10 \%)$ & $(+0 \%)$ & yes \\
Information on employer's & no & no & yes & 10 \\
surplus & 10 & 10 & 17 & 19 \\
Number of subjects & 10 & & & \\
\hline \hline
\end{tabular}

The information on the employer's surplus from the employee's work effort was implemented by exactly specifying the employer's opportunity costs. The instructions explicitly stated that the experimenter had to pay Euro 0.06 in case of outsourcing the task. This cost was

\footnotetext{
10 Subjects were informed that the letter was part of an information mailing for an upcoming research conference.

${ }^{11}$ The formulation of the instructions was as close as possible to the instructions of the field experiment.
} 
determined in a pre-session in which students were asked to do the same work task. The unit cost of a letter was calculated based on the wage of university student employees.

To facilitate the calculation of the employer's surplus, the instructions of the treatments L0surplus and L10surplus included a table of the employer's average cost per letter, depending on the number of envelopes filled per work unit (see table 4). In addition, it was explicitly mentioned that, compared to outsourcing, the employer's break even was at a production of 41 (45) letters per subject per work unit in L0surplus (L10surplus, respectively).

Table 4. Average cost of production (displayed in the surplus information treatments only)

\begin{tabular}{llllllllllllllllll}
\hline \hline $\begin{array}{l}\text { Number of } \\
\text { letters }\end{array}$ & 15 & 20 & 25 & 30 & 35 & 40 & 45 & 50 & 55 & 60 & 65 & 70 & 75 & 80 & 85 & 90 \\
\hline $\begin{array}{l}\text { Average cost } \\
\text { per letter in } \\
\begin{array}{l}\text { Cents } \\
\text { L10surplus }\end{array}\end{array}$ & 16.7 & 12.5 & 10.0 & 8.3 & 7.1 & 6.3 & 5.6 & 5.0 & 4.5 & 4.2 & 3.8 & 3.6 & 3.3 & 3.1 & 2.9 & 2.8 \\
$\begin{array}{l}\text { average cost } \\
\text { per letter in } \\
\begin{array}{l}\text { Cents (2 } \\
\text { work unit) }\end{array}\end{array}$ & 18.3 & 13.8 & 11.0 & 9.2 & 7.9 & 6.9 & 6.1 & 5.5 & 5.0 & 4.6 & 4.2 & 3.9 & 3.7 & 3.4 & 3.2 & 3.1 \\
\hline \hline
\end{tabular}

\subsection{Results of the laboratory experiment}

Work output is measured by the number of filled envelopes. Due to the simplicity of the task, we did not observe any output waste. Hence, there is no difference in the measurement of output quantity and quality. In order to correct for individual capabilities of the workers, we base the evaluation on the difference in work output of the two work units, i.e. before and after the wage increase. In the no-surplus information treatments L0 and L10, average output increases by 10 and 9.9 envelopes, respectively. In the information treatments L0surplus and L10surplus, our experimental workers filled 6.2 and 12.9 envelopes, respectively.

In all four treatments, we find an experience effect: Subjects' output quantity in the second work unit is significantly higher than in the first unit (in each treatment $p \leq .001$, Wilcoxon signed rank test, two-tailed). Nonetheless, the question is whether in addition to the experience effect there is also a treatment effect. To analyze the impact of surplus information and wage increase on output, we compare the output increases across treatments. For each treatment, the vertical line in Figure 2 visualizes the range of output changes, and the horizontal line marks average output. 
The impact of a wage increase in the absence of surplus information is analyzed by comparing L0 to L10. As expected from our field experiment, we find no significant difference in the work output increase $(\mathrm{p}=.836$, two-sided, Mann Whitney U-test). Obviously we have replicated the finding of our field experiment that in the absence of surplus information, a positive wage-effort relation is not observed.

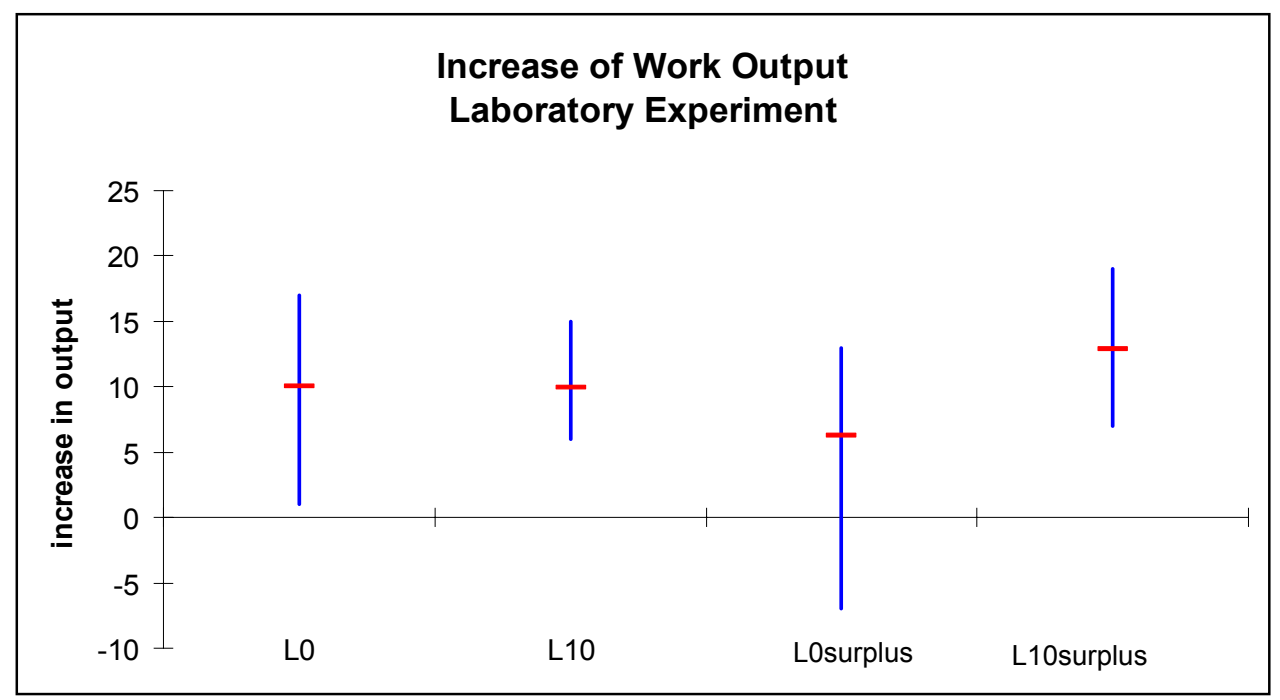

Figure 2: Increase of work output in the laboratory experiment

If surplus information is provided, the picture is clearly different. The wage increase from the first to the second work unit leads to an increase in output of only 6.2 envelopes in L0surplus. In L10surplus, however, the absolute output increase more than doubles. This difference is highly significant ( $\mathrm{p}=0.001$, Mann Whitney U-test, two-sided). Hence, with explicit surplus information, we observe a strong positive wage-effort relationship.

Before reaching a final conclusion, it is important to check whether surplus information per se has an impact on the increase in output. This can be analysed by comparing treatment L0 with L0surplus and treatment L10 with L10surplus. The first comparison reveals that surplus information in absence of a wage increase does not yield a significant output increase $(p=0.235$, Mann Whitney U-test, two-sided). Only when wages are raised, surplus information leads to a significantly higher work output ( $\mathrm{p}=0.043$, Mann Whitney U-test, two-sided).

An important question for the employer is whether in case of a positive wage effort relation, the increased output compensates for the higher wage expenses. Obviously, in the absence of surplus information (comparison L0 to L10) the higher wage is not recouped. In case of 
surplus information, however, the wage increase by 0.25 cents pays off if at least four additional envelopes are produced. Beyond the experience effect (also observed in L0surplus), however, we observe an average increase by 6.7 envelopes. Hence, in case of surplus information the expenses for the wage increase are more than compensated by the output increase.

\section{Conclusion}

Our study provides two major insights into the empirical relevance of the fair wage-effort model. First, our laboratory experiment supplies further support for reciprocal behavior in labor relationships. Wage increases lead to a substantially increased output in our real effort setting. In fact, we find that wage hikes can be profitable for the employer. This positive wage-effort relationship, however, is only observed when there is unambiguous information on all parties' cost and benefits. In lack of employer surplus information, employees do not respond reciprocally, i.e. with increased output to increased wage.

This latter finding is the second major insight from our study, for which we not only find evidence in our real-effort laboratory experiment, but also in our extensive field experiment. There, neither variations of own wages nor variations of peer income information lead to changes in the work output. We conclude that reciprocal employee behavior can provide financial benefits for employers, but only if there is sufficient information about the distribution of surplus.

Our study gives strong support for the positive impact of firm's internal profit information policy on work output. This seems to be due to the fact that if employees are not able to assess how the gains from trade are distributed, they do not have a reference point for being reciprocal. In long-term relationships, however, the missing-information effect may be mediated, because employees improve their information on the income distribution by experience. In addition to reputational considerations, this information effect can be another reason why the fair wage-effort model is more suitable for long-term than for short-term labor relationships.

It is evident that our experiments only allow to draw qualitative conclusions on the validity of the fair wage-effort hypothesis, and not to assess the distribution of the corresponding parameters in real labor markets. We will have to leave this task to future empirical research. 


\section{References}

ADAMS, J. Stacy (1963): Towards an Understanding of Inequity, Journal of Abnormal and Social Psychology, 67, 422-436.

Adams, J. Stacy, and W.B. Rosenbaum (1962): The Relationship of Worker Productivity to Cognitive Dissonance about Wage Inequities, Journal of Applied Psychology, 46, 161-164S.

AKERLOF, George A. (1982): Labor Contracts as Partial Gift Exchange. Quarterly Journal of Economics, 97, 543-569.

AKERLOF, George A. and Janet L. Yellen (1990): The Fair Wage-Effort Hypothesis and Unemployment, Quarterly Journal of Economics, 105, 255-283.

CHARNESS, Gary (2004): Attribution and Reciprocity in an Experimental Labor Market, Journal of Labor Economics, 22, 665-688.

Charness, Gary, and Peter KuHn (2004): Do Co-Workers' Wages Matter? Theory and Evidence on Wage Secrecy, Wage Compression and Effort, Working paper, University of California, Santa Barbara.

Dickinson, David L. (1999): An Experimental Examination of Labor Supply and Work Intensities, Journal of Labor Economics, 17, 638-670.

EREV, Ido, Gary BORNSTEIN and Racheli GALILI (1993): Constructive Intergroup Competition as a Solution to the Free Rider Problem: A Field Experiment, Journal of Experimental Social Psychology, 29, 463-478.

FAHR, René, and Bernd IRLENBUSCH (2000): Fairness as a Constraint on Trust and Reciprocity. Economics Letters, 66, 275-282.

FALK, Armin, and Andrea ICHINO (2003): Clean Evidence on Peer Effects, IZA Discussion Paper No. 732.

FEHR, Ernst, and Felix GÖTTE (2002): Do Workers Work More if Wages Are High? Evidence from a Randomized Field Experiment, Working Paper No. 125, Institute for Empirical Research in Economics, University of Zurich.

FEHR, Ernst, and Armin FALK (1999): Wage Rigidities in a Competitive Incomplete Contract Market. An Experimental Investigation. Journal of Political Economy, 107, 106-134.

FEHR, Ernst, Erich KIRCHLER, Andreas WeICHBOLD, and Simon GÄCHTER (1998): When Social Norms Overpower Competition: Gift Exchange in Experimental Markets, Journal of Labor Economics, 16, 312-354.

GNEEZY, Uri (2004): Do High Wages Lead to High Profits? An Experimental Study of Reciprocity Using Real Effort, University of Chicago Graduate School of Business Working Paper.

HARRISON Glenn W. and John A. LIST (2004): Field Experiments, Journal of Economic Literature, 42, 1009-1055

IRLENBUSCH, Bernd and Dirk SLIWKA (2003): "Transparency and Reciprocal Behavior in Employment Relations," Discussion Paper 2003-009E, University of Erfurt.

MitzKewitz, Michael, and Rosemarie NAGEL (1993): Experimental Results on Ultimatum Games with Incomplete Information, International Journal of Game Theory, 22, 171-198.

SuMMERS, Lawrence H. (1988): Relative Wages, Efficiency Wages and Keynesian Unemployment, American Economic Review, Papers and Proceedings, 78, 383-388. 


\section{Appendix A}

Table A1: Statistical comparison of output measures

\begin{tabular}{ccccc}
\hline \hline Change in variable & F0 vs. F10 & $\begin{array}{c}\text { F10 vs. } \\
\text { F40peer }\end{array}$ & $\begin{array}{c}\text { F10 vs. } \\
\text { F10peer }\end{array}$ & $\begin{array}{c}\text { F40peer vs. } \\
\text { F10peer }\end{array}$ \\
\hline $\begin{array}{c}\text { Output difference } \\
\text { usable output }\end{array}$ & .290 & .656 & .734 & .893 \\
output quality & .744 & .499 & .961 & .424 \\
\hline Output ratio & & & & \\
usable output & .366 & .553 & .719 & .835 \\
output quality & .744 & .526 & .961 & .424 \\
\hline
\end{tabular}

The entries denote the p-values of the two-tailed Mann-Whitney U-Test

There is also no difference between treatments according to the Kruskal-Wallis test for both the difference $\left[2^{\text {nd }}\right.$ minus $1^{\text {st }}$ hour $]$ in usable output $(p=.827)$ and output quality $(p=.881)$.

\section{Appendix B: Instructions}

\section{B1. Field Experiment}

The Economics Research Center „Information and Coordination of Economic Activities“ (SFB 303) has been existing during the past 15 years. Most professors and assistants of the Bonn economics department are collaborating in the SFB 303. Within these years a huge amount of working papers have been written reporting on the research done in the Economics Research Center. To make research results accessible to other scientists in a more effective way than before, the abstracts of all research papers shall be available via Internet by mid- 2000 . Recently submitted papers do not raise any problems because the author electronically submits the abstract together with the paper. Difficulties arise, however, with older discussion papers either providing no abstract at all or at least no typed version. Most authors have left the University of Bonn already. In order to give electronic access also to these abstracts we initiated the project Electronic Abstract Documentation.

\section{Your task}

You will receive a folder containing abstracts of older papers the authors did not submit electronically. In addition, you will find abstracts which have been created by extracting the important results of the research paper. Your task is to enter the abstracts into the word processor from which they will be transferred to the Internet. We hope you understand that the SFB 303 wants to present itself in the Internet by correctly typed abstracts only. Therefore please take care to enter the abtracts from the folder without any mistakes.

\section{Organization}

This is a pilot study on the division of work load. Many students collaborate in this study for two working hours each. Everybody works for these two hours at two different occasions as already has been arranged with you. In the following, you will be introduced to the task you are going to perform, and you will have the opportunity to familiarize yourself with the word processor by typing an abstract for training. Introduction and training must not exceed 20 minutes.

After having completed the training phase, you have 60 minutes time to enter the abstracts from the file. You will be notified by the project coordinator when the time is over. Please stop typing even if you did not finish the abstract you are working on because we otherwise will not be able to keep our time schedule. 


\section{Payment}

You will be paid after having completed the second working hour. You will receive DM 10 for the instruction and training phase plus a wage for each working hour of DM 20 for typing.

If you have any questions or if any technical problems arise please immediately call the project coordinator whom you find in the room next to this office.

\section{Information to typists for the 2nd working hour}

\section{Treatment F0}

this is a reminder that the payment for the second working hour is DM 20.

\section{Treatment F10}

we are happy to inform you that due to a favorable development in the funding of the project we are able to remunerate your experience. We therefore can raise the payment for the second working hour by $10 \%$ to DM 22.

\section{Treatment F40peer}

we are happy to inform you that due to a favorable development in the funding of the project we are able to remunerate your experience. As you may have heard already, we could previously raise the payment for the second hour of work by $10 \%$ to DM 22 . Unexpectedly, additional funding became available for the project. Therefore we decided to once more raise the payment for the second working hour, namely by all in all $40 \%$ to DM 28.

\section{Treatment F10peer}

we are happy to inform you that due to a favourable development in the funding of the project we are able to remunerate your experience. As you may have heard already we could previously raise the payment for the second hour of work by $40 \%$ to DM 28 . Unexpectedly, less funding became available for the project. We are sorry that for this reason we can raise the payment for the second working hour only by 10\% to DM 22 .

\section{B2. Laboratory Experiment}

Those parts of the instruction that are written in italics are relevant for the surplus information treatment only.

This year, the department of Microeconomics is organizing an international conference on experimental economics. For this reason, a large amount of information letters has to be mailed to people interested in the conference.

\section{Your task}

You will receive a pile of information sheets as well as a pile of envelopes. Your task is to fold the information sheets twice, put them into the envelopes and close the envelopes. We hope you understand that the department wants to present itself by correct information letters only. Therefore we ask you to carefully put the sheets into the envelopes.

\section{The Organisation}

This is a pilot study on the division of work load. Many students collaborate in this study for two working units of 15 minutes each. Between the working units, there is a break of 5 minutes. After the introduction, you will be introduced into the task you are going to perform. Introduction and training must not exceed 10 minutes.

\section{Payment}

You will be paid after having completed the second working unit. You will receive $€ 1,50$ for the instruction plus a wage of $€ 2,50$ for each working unit. 


\section{Surplus for the department}

If the department had the task being completed by someone else, costs of 6 Euro Cents per letter would occur. The department decided, however, to hand this task over to you on a flat fee basis. The table below shows the costs per letter depending on the number of completed letters per work unit the department encounters by paying you you $€ 2,50$. In order to create a surplus for the department, you would have to complete more than 41 letters in one work unit (i.e. in 15 minutes).

\begin{tabular}{lllllllllllllllll}
\hline $\begin{array}{l}\text { number of } \\
\text { letters }\end{array}$ & 15 & 20 & 25 & 30 & 35 & 40 & 45 & 50 & 55 & 60 & 65 & 70 & 75 & 80 & 85 & 90 \\
\hline $\begin{array}{l}\text { cost per letter } \\
\text { in Centss }\end{array}$ & 16,7 & 12,5 & 10,0 & 8,3 & 7,1 & 6,3 & 5,6 & 5,0 & 4,5 & 4,2 & 3,8 & 3,6 & 3,3 & 3,1 & 2,9 & 2,8 \\
\hline
\end{tabular}

\section{Any further questions?}

If you have any questions, please ask the project coordinator.

\section{Information on the wage for the 2 nd working unit}

\section{Treatments LO and LOsurplus}

To remind you: the payment for the second working hour is $€ 2,50$.

If the department had the task being completed by someone else, costs of 6 Euro Cents per letter would occur. The table below shows the costs per letter depending on the number of completed letters per work unit the department encounters by paying you $€ 2,50$. In order to create a surplus for the department you would have to complete more than 41 letters in one work unit (i.e. in 15 minutes).

\begin{tabular}{lllllllllllllllll}
\hline $\begin{array}{l}\text { number of } \\
\text { letters }\end{array}$ & 15 & 20 & 25 & 30 & 35 & 40 & 45 & 50 & 55 & 60 & 65 & 70 & 75 & 80 & 85 & 90 \\
\hline $\begin{array}{l}\text { cost per letter } \\
\text { in Cents }\end{array}$ & 16,7 & 12,5 & 10,0 & 8,3 & 7,1 & 6,3 & 5,6 & 5,0 & 4,5 & 4,2 & 3,8 & 3,6 & 3,3 & 3,1 & 2,9 & 2,8 \\
\hline
\end{tabular}

\section{Treatments L10 and L10surplus}

We are able to remunerate your experience and therefore can raise the payment for the second working unit by $10 \%$ to $€ 2,75$.

By raising your payment higher costs occur to the department.

If the department had the task being completed by someone else, costs of 6 Euro Cents per letter would occur. The table below shows the costs per letter depending on the number of completed letters per work unit the department encounters by paying you $€ 2,75$. In order to create a surplus for the department you would have to complete more than 45 letters in one work unit (i.e. in 15 minutes).

\begin{tabular}{lllllllllllllllll}
\hline $\begin{array}{l}\text { number of } \\
\text { letters }\end{array}$ & 15 & 20 & 25 & 30 & 35 & 40 & 45 & 50 & 55 & 60 & 65 & 70 & 75 & 80 & 85 & 90 \\
\hline $\begin{array}{l}\text { cost per letter } \\
\text { in Cents }\end{array}$ & 18,3 & 13,8 & 11,0 & 9,2 & 7,9 & 6,9 & 6,1 & 5,5 & 5,0 & 4,6 & 4,2 & 3,9 & 3,7 & 3,4 & 3,2 & 3,1 \\
\hline
\end{tabular}

